\title{
Organo-Metallic, Phosphorus, Boron Derivatives
}

National Cancer Institute

\section{Source}

National Cancer Institute. Organo-Metallic, Phosphorus, Boron Derivatives. NCI

Thesaurus. Code C1911.

Org anic compounds that contains phosphorus and a metal-carbon bond with Boron atoms. $(\mathrm{NCl})$ 